University for Business and Technology in Kosovo

UBT Knowledge Center

UBT International Conference

2014 UBT International Conference

Nov 8th, 5:00 PM - 5:15 PM

\title{
Monitoring of Water Losses and Leakages in one Zone (DMA) in Prishtina city - Dardania
}

Ilir Abdullahu

University for Business and Technology

Muhamet Ahmeti

University for Business and Technology

Follow this and additional works at: https://knowledgecenter.ubt-uni.net/conference

Part of the Architecture Commons

\section{Recommended Citation}

Abdullahu, llir and Ahmeti, Muhamet, "Monitoring of Water Losses and Leakages in one Zone (DMA) in Prishtina city - Dardania" (2014). UBT International Conference. 20.

https://knowledgecenter.ubt-uni.net/conference/2014/all-events/20

This Event is brought to you for free and open access by the Publication and Journals at UBT Knowledge Center. It has been accepted for inclusion in UBT International Conference by an authorized administrator of UBT Knowledge Center. For more information, please contact knowledge.center@ubt-uni.net. 


\title{
Monitoring of Water Losses and Leakages in one Zone (DMA) in Prishtina city - Dardania
}

\author{
Ilir Abdullahu ${ }^{1}$ Muhamet Ahmeti ${ }^{2}$ \\ ${ }^{12}$ Faculty of Civil Eng.\& Architecture, UBT Prishtinë
}

\begin{abstract}
Reduction of water losses is one of the biggest challenges today in the industry of water treatment. Large amount of raw water is lost and thus the loss has very high cost and increases shortages of regular water supply. Today's world faces the loss of water and the best situation is in developed countries, while in developing countries and undeveloped ones, water loss is in the rate of $>50 \%$.

Thesis will present practical experience in reducing technical losses in a measuring area (DMA) in Regional Water Company "Prishtina", where losses now have a trend towards reduction.

Monitoring of flow and pressure is done and continues to be done with sophisticated devices such as Corelator, Detector of noise, Data-Logger, Locators and respective software which enable the exact location of leakage. These practices of technical loss reduction are followed in countries that are advanced in this respect and are transferred and continue to advance in Regional Water Company Prishtina. Results of research will have the followings:
\end{abstract}

Keywords: DMA, Pristina, Water Losses

\section{Introduction}

Water loss can be controlled only by a full activity in different parts of the water distribution system, including necessary improvement to efficient management system, organization and education within the water utility companies.Today at our disposal is the latest global knowledge known as IWA methodology that provides a realistic perception of the problem and selection of appropriate methods to control and reduce water losses, as well as a variety of technical and technological solutions, but what is mentioned above does not guarantee a successful implementation of the program and achieving goals. A key element of any program is men, and without proper training, coordination and control is not realistic to expect positive results. Therefore, it is important for successful planning and implementation of subsequent activities; improve the ability/human capacity who works in companies that provides water services which includes advanced knowledge and new skills in such areas as it is the reduction of technical losses in distribution networks. Today, all these disciplines are known, but managing skills are still rare to be implemented in an efficient way from the utilities of water service providers in the field of water loss control. In this document, we want to emphasize skills of management based on description and implementation of applicable practices. We want to give special emphasis to the need for continuous increase of people in public utility water companies to be more independent and successful in daily activities.

\section{What are the problems we face on reducing water losses}

In some of our basic services (and typical) problems of effective control of water loss may occur in the following categories:

- Inactive control of losses

- Lack of understanding about the complexity of water losses (and use of non-revenue water in \% of general volume (at the inlet) as main or the only performance indicator).

- Insufficient and slow technological development

- Lack of an action strategy (program) to reduce (control) water losses. 
- Companies to solve the problem of water loss are still including only the work-tasks that are often based solely on passive flow control (dealing only with reported leaks).

- A work team or a qualified person (responsible) for leak detection activities on the network (basic trainings for device applications) would be very desirable to increase the higher level of controlling water losses from production systems up to the distribution network.

- Regional Water Company"Prishtina" j.s.c., has basic equipment for leak detection (site microphone, correlator, other devices for measuring pressure and water flow at the zone).

- Information on the leaks are taken through notices of the existence of problems in the system (pressure decrease, water loss, appearance of water into the ground or elsewhere, etc.) or after periodic readings of consumption and increasing the level of non-revenue water (changes).

- Departments responsible on leak maintenance and repair, but without appropriate statistical records also shows more weakness.**

- Critical challenge for services is the lack of strategies or programs for control of water loss at the highest level in the company. What is still not going well is the activity of controlling water losses is not assessed in sufficient level, except in cases of insufficient water capacities or high cost of maintenance. The connection between problems and challenges presented is the man, his capacities, skills, efficiency and willingness for continuous improvement.

\section{The solution of the problem}

Inability of insufficient efficiency of water supply of our companies on control and reduction of water loss can be found on the following plans:

- Creating a strategy/program of continuous operation in the field of water loss control

- Acquiring knowledge and management skills

- Continuous training in the field of methodology and technology

- Implement strategies/programs necessary to change existing practices

- Benchmarking Application (efficiency and control results)

Adoption and implementation of active management skills is a basic and essential step for effective action on controlling and reducing water losses. Although this idea seems logical and simple, it is a major challenge to our companies that provides water services. In particular, long-term management practices in the context of the existing human resources (with a constant decrease of the number of high quality and motivated people) are a serious problem that must be handled with special care.

\section{Knowledge and skills on managing controlled water losses}

I want to emphasize the following key categories of managing skills necessary an efficient control of water losses.

\section{Project Management}

- The discipline of planning, organization, security and managing of resources to support the successful completion of the project and the achievement of objectives. It should be emphasized that water loss project is subject to continuous improvement and can consist of the following elements:

- Planning of measures and activities with maximum utilization of all available resources

- Implementation of long-term objectives (3-5 years)

- Implementation of short-term objectives (1-3 years)

- Gathering information and analysis

- Implementation processes in four basic steps: planning, implementation, analysis, correctness

- Organizational changes within the Company

- Ongoing - practical work in a zone of the capital city Prishtina 


\subsection{DMA- DARDANIA - Prishtine - Kosovo}

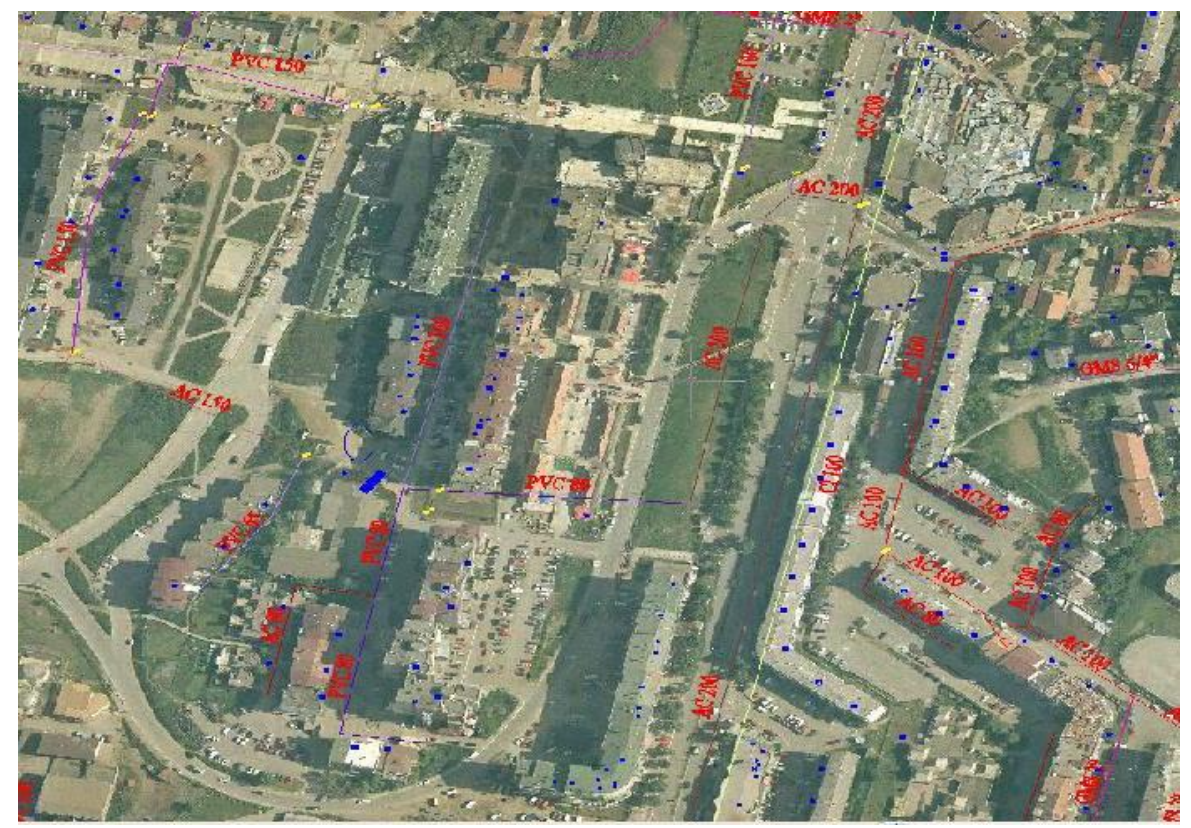

Fig1. Analysis of water losses in a small zone of Dardania district:

Database for the zone

- No. of apartments. .460

- No. of inhabitants.......................... 3000

- Length of primary pipes... $\mathrm{L}=450 \mathrm{~m}$

- Density of connections nr/m.....19

- Collective connections........................ $\mathrm{Nr}=24$

\subsection{Pressure Zone 2 Lok/Dardania-Collective Apartments Near PTK}

Pipe PE-100 PN-12 OD-160mm....Supply zone, pipe installed during the year 2001

Pipe PE-100 PN-12 OD-75mm

Pipe PE-100 PN-12 OD-63mm

Pipe AC-TIP-C......DN-80mm

Zone water meter....... DN-150mm

Local water meter..........2“,6/4“ ”,5/4“ ,1“ ,3/4”

EQUIPMENT FOR MEASUREMENT IN THE ZONE

Data-logger for monitoring of leakage in the zone installed in zone water meter- Data-logger for monitoring of pressure zone

Data-logger for monitoring of pressure zone 


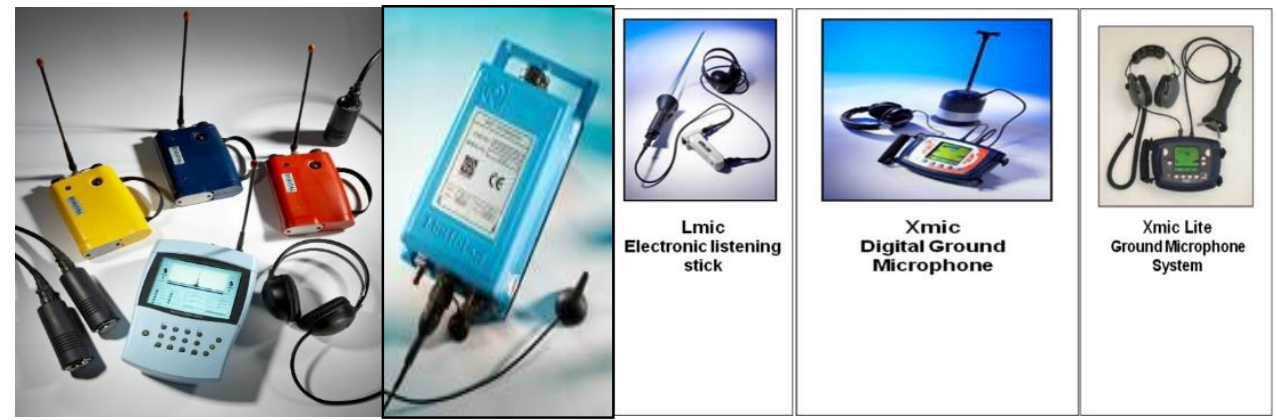

Fig.2 Equipment for Detection

\section{Leak Detection- Correlation}

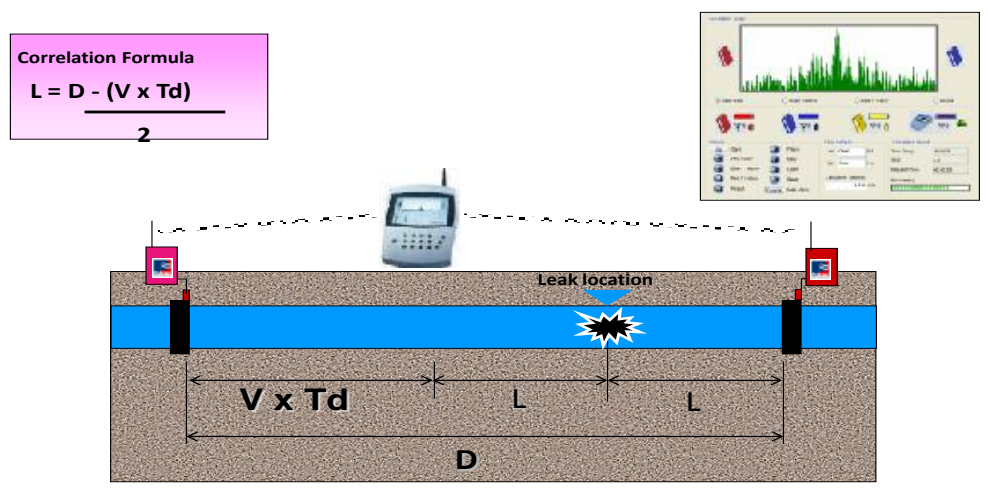

Fig.3 Correlator

DMA-Monitored Measurements in the zone-Pressure Monitoring

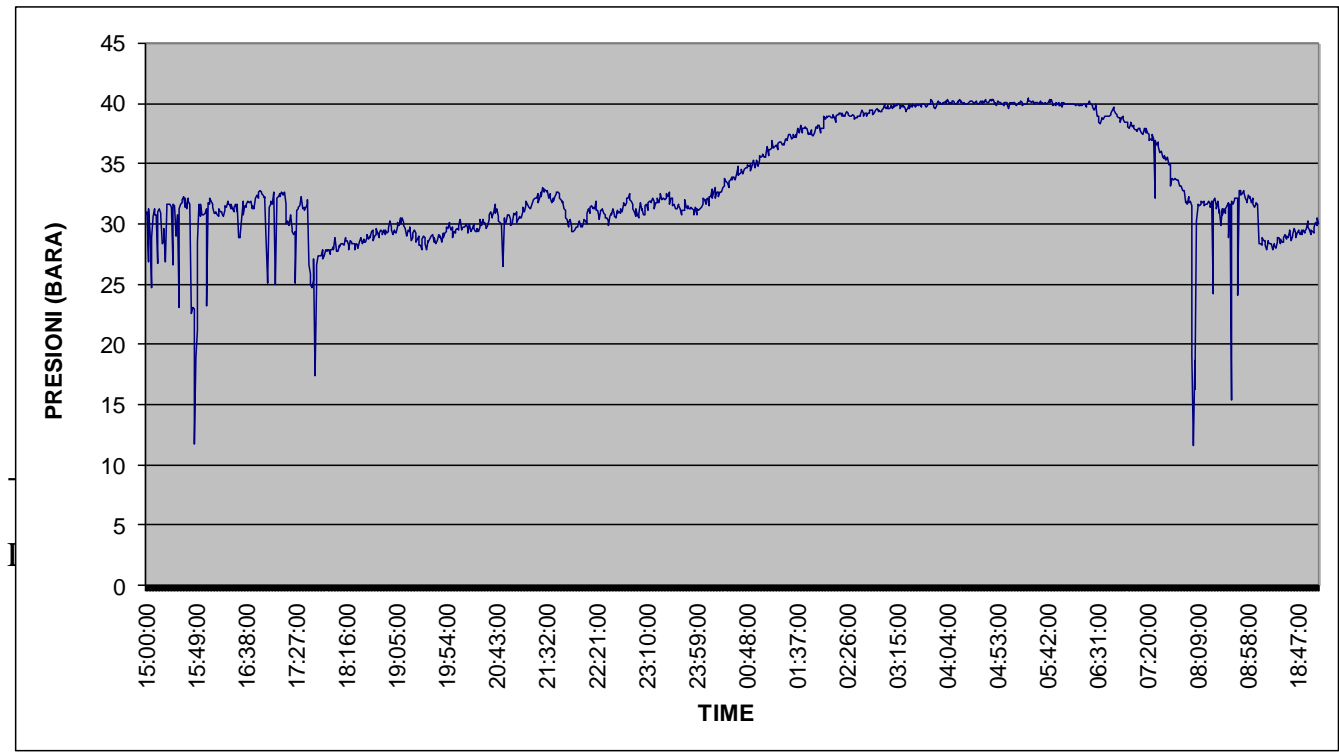




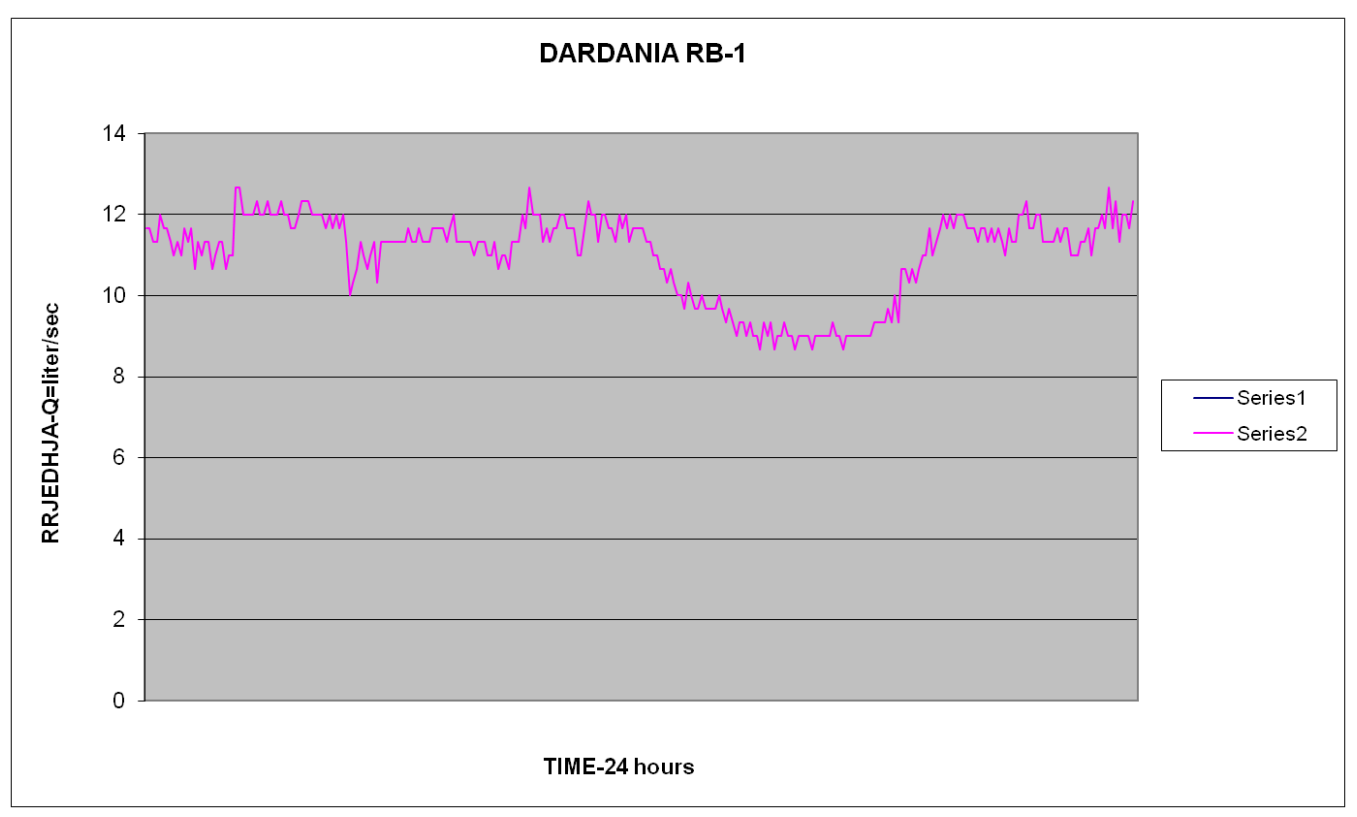

In flow metering graph we see the relation of night Pressure/Flow between Pmax/Fmin when night consumption is above the expected consumption, and it is much higher, even after the evaluation $3 \%$ of customers are active during the night in this area for which measuring period is 02-04 am.

\section{Zone inspection-repair of possible leakages}

One week inspection in the zone

Leakage inspectors engaged with Leakage detection equipment. Inspection results:

- $\quad$ Leakages in zone.......................6 6

- External Leakages ........................ 2

- Internal Leakages..............................4

- $\quad$ Leakage repairs...........................6 


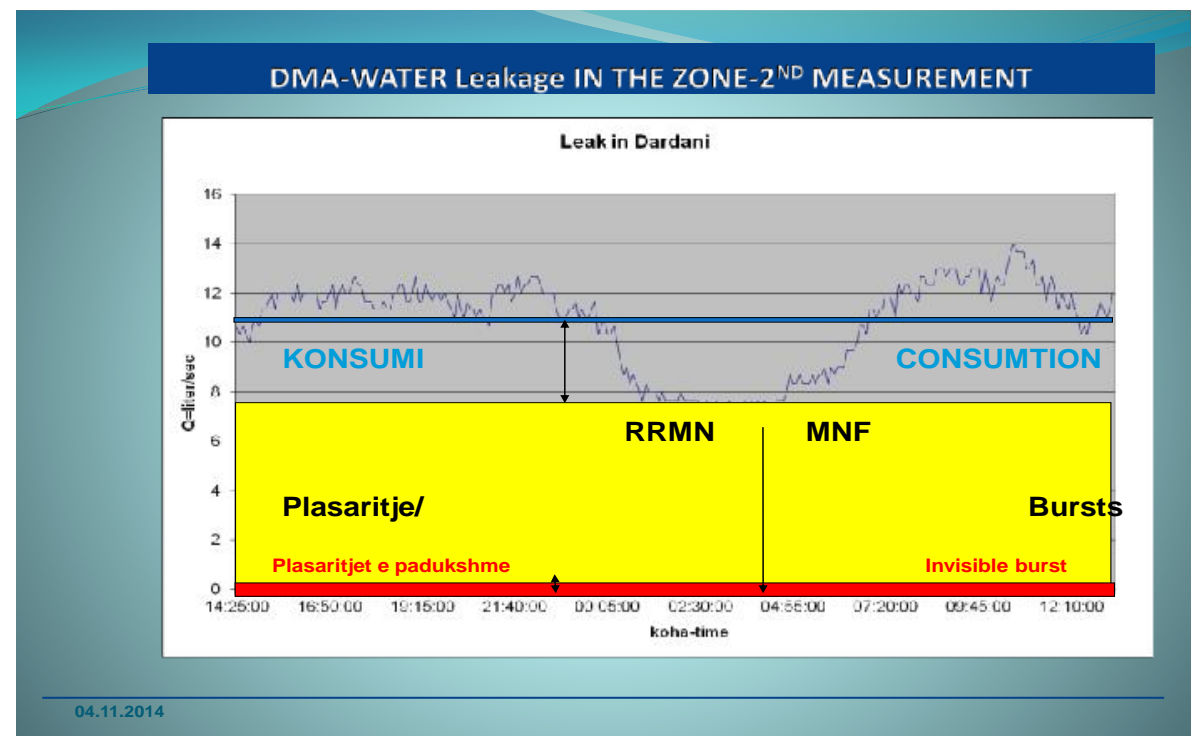

Graph 3 gives clear data regarding loss determination in distributive network in the area of Dardania. The red line represents background leakages, whereas the yellow line represents loss rate in the area and consumption for inhabitants in the area.

\subsection{Analysis of monitoring of technical losses in water network}

Average pressure $(\mathrm{PM})=3.5 \mathrm{~B}$ ara

Total Fllow/day....Q $=853 \mathrm{~m} 3 /$ day

Total Fllow/month...Q $=25585 / \mathrm{m}^{3}$ month

Monthly bill for an apartment is 16.69 euro

Consumption per person...Q=284 litra/day

Reading for local water meter for one month is with this quantity $Q=21628 \mathrm{~m}^{3}$ invoiced

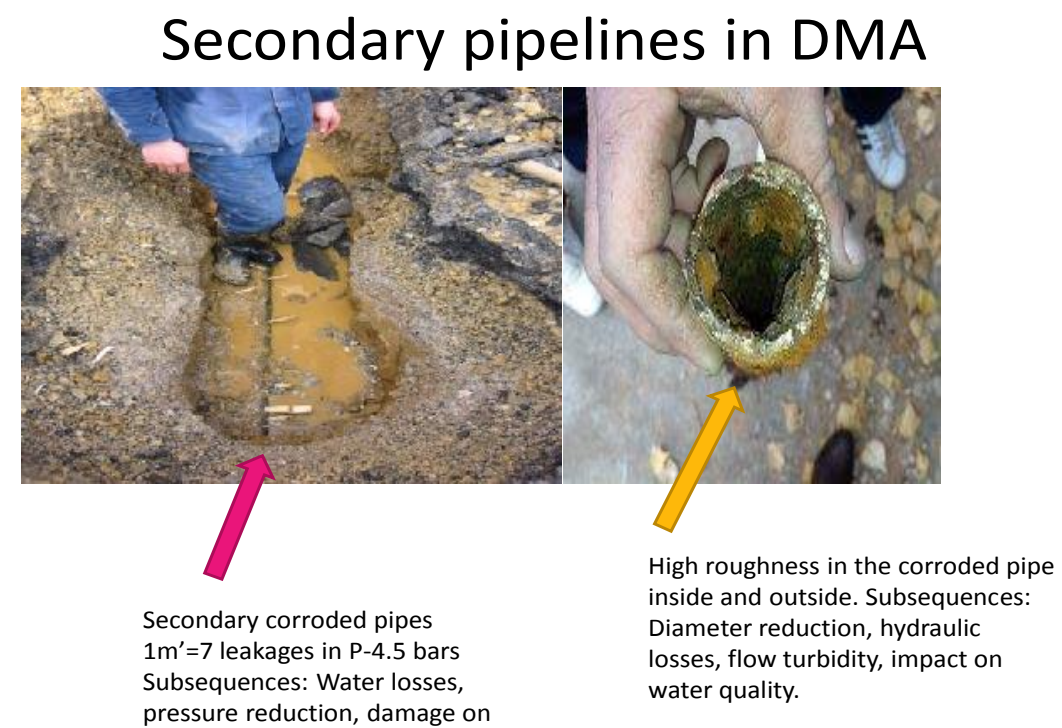

Fig.4 (a and b). Condition of secondary pipeline and high roughness. 

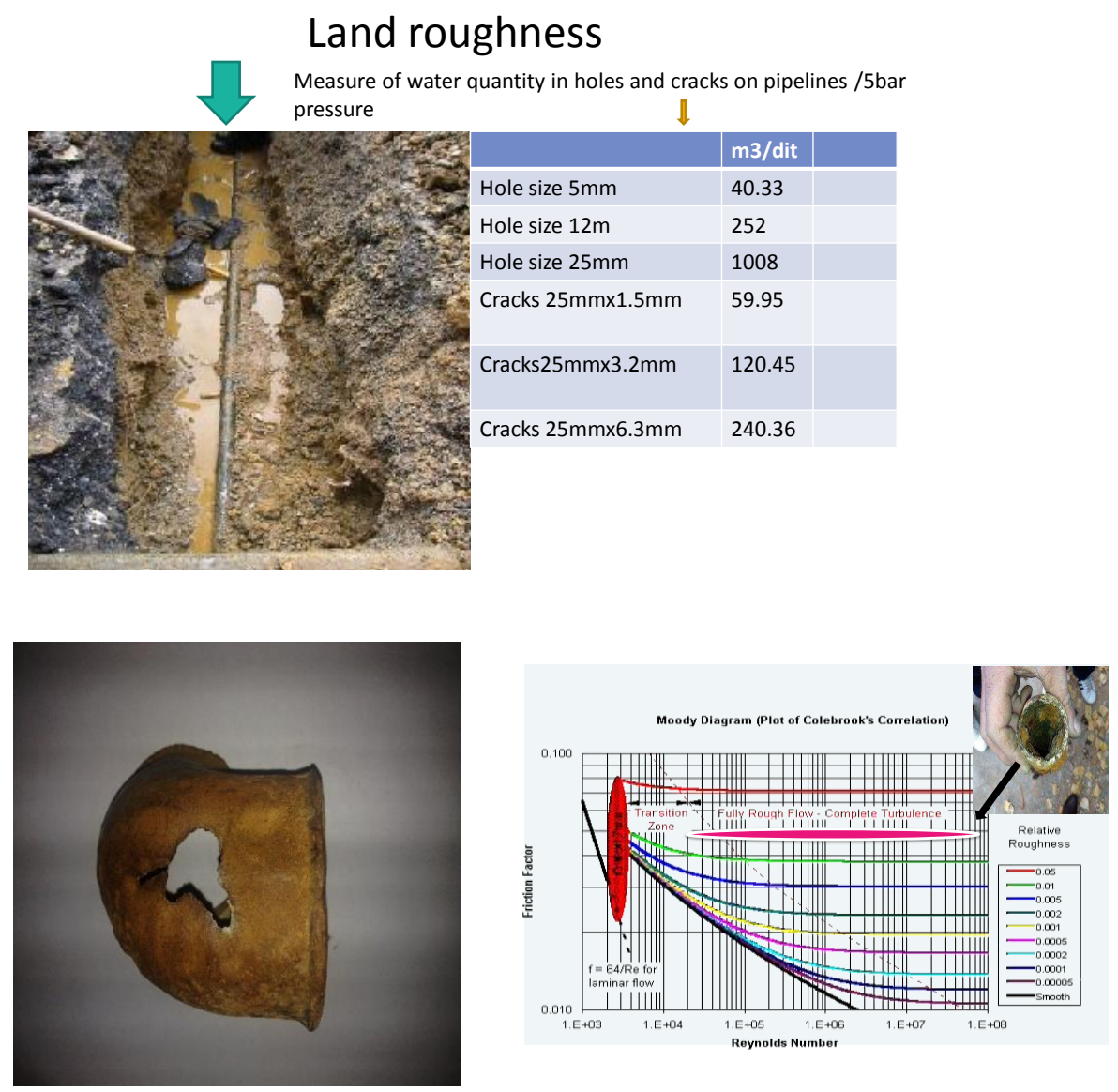

Fig.5a Pipeline and flow apacity in different holes, 5b. Pipe age and high level corrosion in metal pipes. 5c Graph Moody Diagram

Hydraulic modeling for old networks in pipelines with high roughness - inaccurate hydraulic parameters

- Number of Reynoldsit : $\quad \frac{\rho D v}{\mu}$

Re $<2100$ Laminar Flow

$\operatorname{Re}>4000$ Turbidity Flow

- Fraction factor:

$$
f=\frac{\Delta P D}{2 \Delta L \rho v^{2}}
$$

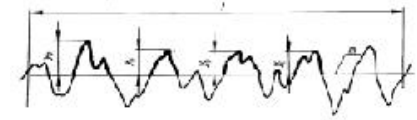

- Roughness factor and laminar flow

$$
f_{F}=\frac{16}{\operatorname{Re}}
$$

- Roughness factor of Colebrook andWhite equation of turbidity flow

$$
\frac{1}{\sqrt{f_{F}}}=-4.0 \log _{10}\left(\frac{\varepsilon}{D}+\frac{4.67}{\operatorname{Re} \sqrt{f_{F}}}\right)+2.28
$$


Corrosion that leads to damage of distribution network

Factors

Street

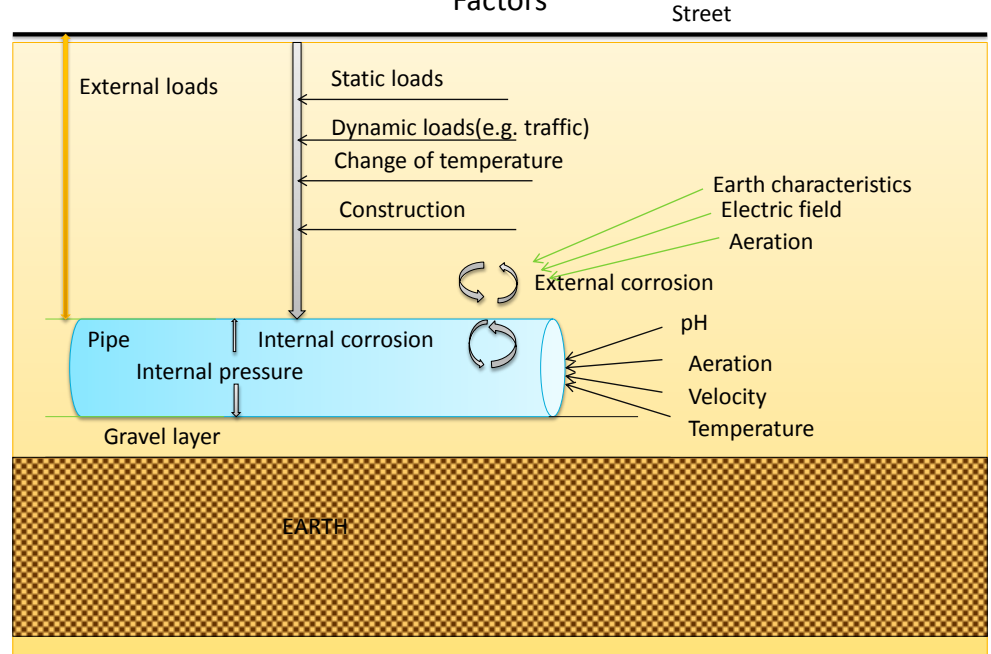

Fig.6 Corrosion that leads to damage of distribution network

Burst from high flow < Low leakages in long period without being repaired

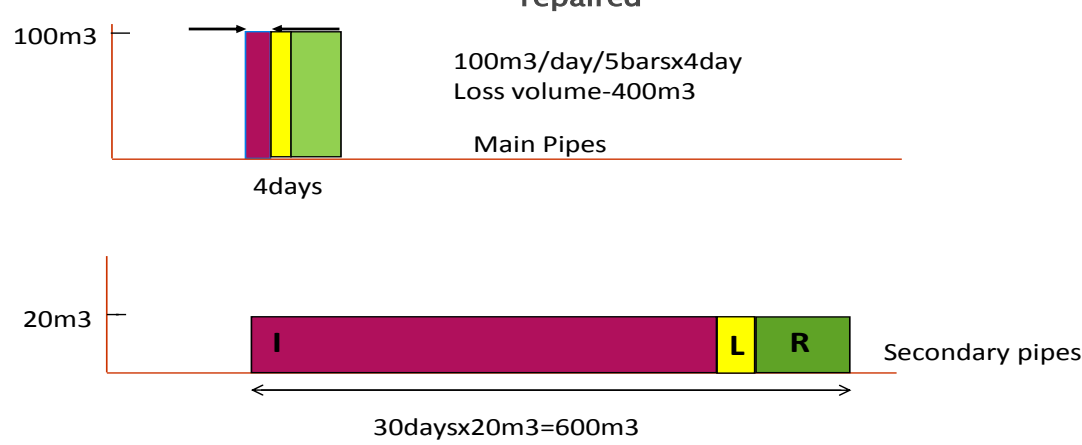

Figure 7 The influence of leak run time on leakage levels. 


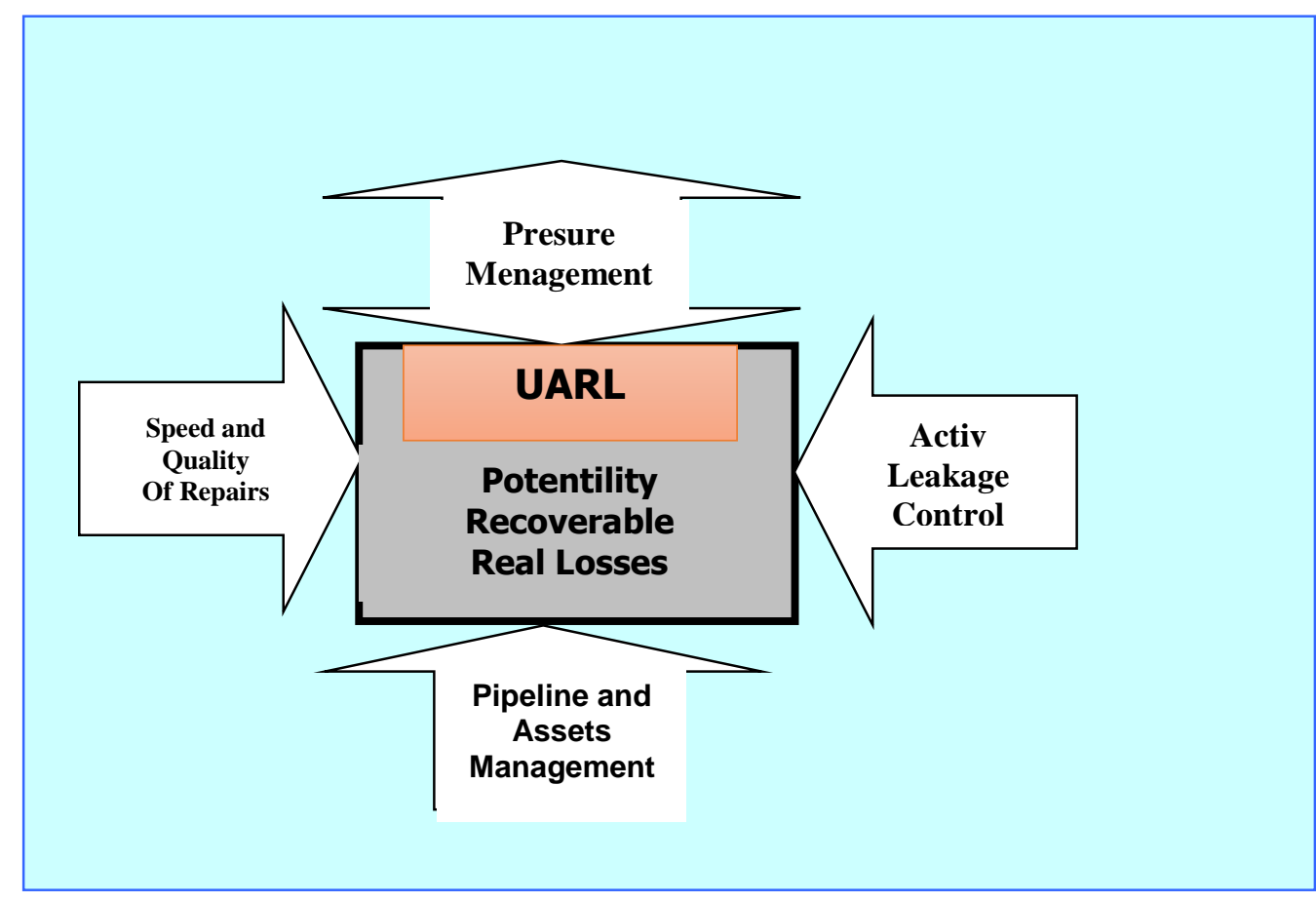

Fig8. The four basic methods of managing real losses

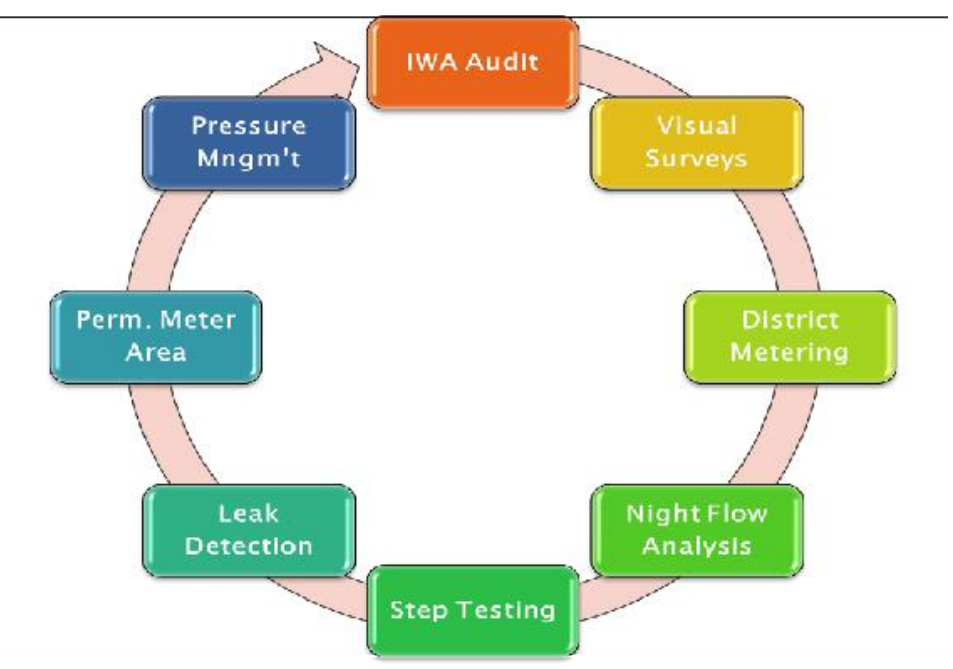

Fig9. A Water Loss Management Cycle 


\section{STANDARD WATER BALANCE-IWA}

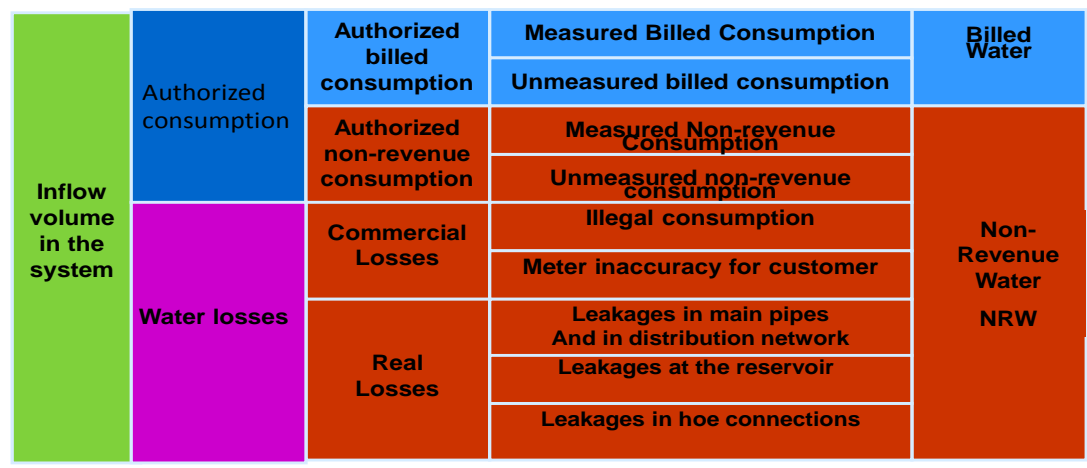

Fig 10. Water Balance(IWA) is the table presentation for NRW for both commercial and technical losses.

\section{Conclusion}

Over consumption is as a result of leakages within water meters starting from vertical pipes and flushing toilets with continuous leakages without any maintenance.

Demand for water in this zone after analysis that are done should be about 4-5 liter/sec.

\section{References}

1. Losses in water Distribution Networks (Malcom Farley and Stuart Trown)

2. Bristol Water plc.(UK)

3. Leak and Break Detection and Repair of Drinking Water Systems(Lawrence A.Smith Keith A.Fields,Abraham S.C. Chen,Anthony N.Tafuri. 